\title{
O papel supervisor dos mediadores dos cursos de educação e formação de adultos: entre o discurso e a prática
}

El papel supervisor de los mediadores de los cursos de educación y formación para adultos: entre el discurso y la práctica

The Supervisory Role of the Mediators of Education and Professional

Development Courses for Adults: between Rhetoric and Practice

Le rôle d'inspecteurs des médiateurs des cours d'éducation et formation pour les adultes: entre la parole et la pratique

Data de recepção: 20 DE FEVEREIRO 20 DE 2013 / Data de aceitação: 6 DE MAIO DE 2015 / Data de disponibilidade on-line: 30 DE OCTUBRE DE 2015

Encontre este artigo em: http://magisinvestigacioneducacion.javeriana.edu.co/

Escrito por Armando Paulo Ferreira-Loureiro Universidade de Trás-os-Montes e Alto Douro VILa Real, Portugal

\section{Resumo}

Na última década surgiu em Portugal um conjunto de novos agentes no campo da educação de adultos. Os mediadores dos cursos EFA são um desses agentes. Este artigo centra-se na análise, a partir de uma pesquisa empírica (assente em entrevistas com mediadores e na observação e registo de reuniões das equipas pedagógicas por eles coordenadas) realizada numa escola, das funções de supervisão inerentes ao seu cargo. Tentar perceber de que modo tais mediadores exercem essas funções foi o propósito dessa investigação. Os resultados levam-nos a concluir que os mediadores que participaram neste estudo atuam de uma forma tendencialmente empírica e que a assunção do exercício da supervisão está mais presente nos seus discursos do que nas suas práticas.

\section{Palavras-chave}

Educação e formação de adultos; conselheiros de educação; supervisão escolar; supervisão dos docentes

\section{Transferência à prática}

Julgamos que o estudo da execução das funções de supervisão inerentes ao papel dos mediadores dos cursos EFA pode ser um contributo para um melhor desempenho destes novos agentes do campo da educação de adultos. Como vimos, no caso pesquisado, os mediadores atuam de uma forma tendencialmente empírica e o exercício da sua função de supervisão está mais presente nos seus discursos do que nas suas práticas. Tal facto pode comprometer este tipo de ofertas educativas. Pelo contrário, uma prática dos mediadores assente numa supervisão reflexiva pode fazer com tais ofertas educativas se aproximem mais dos reais interesses dos adultos que as frequentam. 
Palabras clave

Educación y formación para adultos; consejeros de educación; supervisión escolar; supervisión de los docentes

\section{Keywords}

Education and professional development for adults; educational advisors; school supervision; supervision of teachers

\section{Resumen}

En la última década surgió en Portugal un conjunto de nuevos agentes en el campo de la educación para adultos. Los mediadores de los cursos EFA son unos de esos agentes. Este artículo se enfoca en el análisis, a partir de una investigación empírica (sustentada en entrevistas con mediadores y en la observación y registro de las reuniones de los equipos pedagógicos coordinados por ellos) realizada en una escuela de las funciones de supervisión inherentes a su cargo. El propósito de esta investigación fue intentar percibir de qué modo estos mediadores ejercen esas funciones. Los resultados nos llevan a concluir que los mediadores que participaron en este estudio actúan de una forma tendencialmente empírica y que la presunción del ejercicio de la supervisión está más presente en el discurso que en la práctica.

\section{Transferencia a la práctica}

Consideramos que el estudio de ejecución de las funciones de supervisión inherentes al papel de los mediadores de los cursos EFA puede ser una contribución para un mejor desempeño de estos nuevos agentes del campo de la educación para adultos. Como vemos, en el caso investigado, los mediadores actúan de una forma tendencialmente empírica y el ejercicio de su función de supervisión está más presente en sus discursos que en sus prácticas. Tal hecho puede comprometer este tipo de ofertas educativas. Por el contrario, una práctica de los mediadores basada en una supervisión reflexiva puede hacer que estas ofertas educativas se acerquen más a los intereses reales de los adultos que las frecuentan.

\section{Abstract}

In the last decade emerged in Portugal a set of new agents within the field of adult ed ucation. EFA courses mediators are among these agents. This article focuses on the analysis of the supervisory functions inherent in their position. This data is based on empirical research held in a school, which is supported by interviews with mediators, observation and recording of meetings of the pedagogical teams coordinated by them. The purpose of this research was to perceive how these mediators exert these functions.We conclude that the mediators who participated in this study act in a tendentiously empirical way, and that the presumption of the exercise of supervision is more present in the discourse than in its practice.

\section{Transfer to practice}

We believe that the study of implementing supervisory functions, inherent to the role of mediators of EFA courses, can contribute to a better performance of these new agents of the field of adult education. In the investigated case, mediators act in a tendentiously empirical way, and the execution of their supervisory functions is more evident in their speeches than in their practices. This fact can compromise this kind of educational offerings. Conversely, a mediators practice based on a reflective supervision can make that these educational offerings come closer to the real interests of adults who frequently access them.

\section{Mots clés}

Education et formation pour adultes; conseillers d'éducation; surveillance scolaire; surveillance des enseignants

\section{Résumé}

Dans la dernière décennie a surgit au Portugal un ensemble de nouveaux agents dans le domaine de l'éducation pour adultes. Les médiateurs des cours EFA sont uns de ces agents. Cet article se penche sur l'analyse; à partir d'une recherche empirique (fondée dans les entretiens avec les médiateurs et dans l'observation et le registre des réunions des équipes pédagogiques coordonnées par eux) la recherche réalisée dans une école, sur les fonctions de surveillance à leur charge. Le propos de cette recherche a été celui de tenter d'apercevoir de quelle manière ces médiateurs exercent ces fonctions. Les résultats nous ont conduits à conclure que les médiateurs qu'ont participés de cette étude agissent d'une façon plutôt empirique et que la présomption de l'exercice de surveillance se trouve plus présente dans la parole que dans la pratique.

\section{Transfert à la pratique}

On considère que l'étude d'exécution des fonctions de surveillance inhérentes au rôle de médiateurs de cours EFA peuvent être une contribution pour un meilleur exercice de ces nouveaux agents du domaine de l'éducation pour les adultes. Tel qu'on le voit dans le cas de la recherche, les médiateurs agissent d'une façon plutôt empirique et l'exercice de leur fonctionne de surveillance est plus présente dans leurs paroles que dans leurs pratiques. Ce fait peut menacer ce type d'offres éducatives. Par contre, une pratique de médiation fondée dans une surveillance réflexive peut faire que ces offres éducatives s'approchent plus aux intérêts réels des adultes qui y sont impliqués. 


\section{Introdução}

Atualmente, a sociedade global, em constante e acelerada mutação, exige cada vez mais de cada um de nós do ponto de vista cognitivo, da seleção, tratamento e uso da informação, da preparação para enfrentar as exigências do mercado de trabalho, e da participação cívica e ética nos grupos e movimentos sociais que nos rodeiam. A escola, neste contexto, deve ser motor de desenvolvimento político, social e económico, absorvendo e refletindo essas mudanças. Numa sociedade avançada do ponto de vista tecnológico e de fácil acesso à informação, é fundamental que a escola promova a mobilização de saberes e o desenvolvimento de variadas competências, facultando as condições que permitam aos seus membros lidar com a complexidade dos saberes e gerir, simultânea e eficazmente, as relações humanas.

Com vista à integração na nova realidade social e económica de adultos com idade igual ou superior a 18 anos, empregados ou desempregados, com escolaridade baixa e com níveis de formação profissional desadequados às exigências do mundo do trabalho, a escola em Portugal abriu-se a novos percursos formativos. Entraram em cena os cursos de Educação e Formação de Adultos (EFA), incluídos na Iniciativa Novas Oportunidades.

Estes cursos possibilitam a dupla certificação dos adultos: escolar e profissional. Podem, por isso, ser classificados neste caso como uma oferta educativa mista (Loureiro, 2008), pois combinam a educação escolar compensatória de adultos (Loureiro, 2008; Quintana, 1995), com a formação profissional (Canário, 1999; Dubar \& Gadéa, 2001; Knox, 1993; Palma \& Flecha, 1998).

Os cursos EFA surgiram, assim, no sentido de elevar os níveis de formação da população adulta portuguesa, uma vez que esta revela baixos níveis de escolaridade e de formação profissional. Ora, sabendo que o nível de educação de base se repercute na falta de determinação e de disponibilidade para avançar em aprendizagens ulteriores e continuadas, este facto cria um défice que se traduz em elevados custos nos padrões de desenvolvimento do nosso país (Gomes, 2006).

Para além de, com estes cursos, se procurar responder a esta preocupação de política educativa nacional, há neles uma outra não tão visível. Trata-se de uma preocupação de política social, mais precisamente de prevenção e de reinserção social. Na verdade, uma parte significativa dos adultos que frequentam estes cursos é beneficiária de subsídios estatais, cujo usufruto depende da frequência destas ofertas educativas. Esta é, aliás, uma tendência internacional da educação de adultos que, como nos alerta Mathias Finger (2008), comporta um sério risco: o de passar a ser encarada como uma mera atividade de reparação social, quando o papel de maior relevo da educação de adultos está na sua participação em processos de mudança social.

Os cursos EFA constituem-se, de acordo com a Portaria 230/2008, de 7 de março, numa ótica de aprendizagem ao longo da vida: em trajetos flexíveis de formação, definidos a partir de processos de Reconhecimento, Validação e Certificação de Competências (RVCC), obtidas anteriormente por via formal, não formal e informal; em percursos formativos que integram uma formação de base e uma formação tecnológica, ou somente uma delas; num modelo de formação por módulos organizados a partir dos referenciais de formação que fazem parte do Catálogo Nacional de Qualificações, mas privilegiando a diferenciação de percursos formativos e a sua integração no ambiente profissional, social e económico dos formandos; e na formação desenvolvida em torno de processos reflexivos e
Artigo descrição | Descripción del
artículo | Article description | Des-
cription de l'article gica, da Universidade de Trás-os-Montes e Alto Douro. 
de obtenção de saberes e competências facilitadoras e impulsionadoras de aprendizagens.

A organização e o desenvolvimento dos cursos EFA assentam, reforça Sandra Pratas Rodrigues (2009), desde a sua criação até à atualidade, em princípios que prezam e valorizam os pressupostos da aprendizagem ao longo da vida, pressupostos esses que estão reconhecidos em vários documentos de âmbito internacional como, por exemplo e de acordo com Reginaldo Manuel Sitoe (2006): o Relatório Learning to Be, da Comissão Internacional para o Desenvolvimento da Educação, produzido pela UNESCO em 1972; o Livro Branco que estabeleceu o ano de 1996 como - Ano Europeu da Educação; e o Memorando sobre Aprendizagens ao Longo da Vida, de 2000, que é um documento de trabalho dos Serviços da Comissão Europeia.

Estes cursos fizeram com que surgisse um novo tipo de agente na área da educação e formação de adultos: o mediador dos cursos EFA. O presente artigo centra-se na análise, a partir de uma pesquisa empírica realizada numa escola, das funções de supervisão inerentes ao seu cargo. Tentar perceber se e como os mediadores exercem essas funções foi o propósito dessa investigação. Na nossa perspetiva o estudo sobre tal problemática poderá contribuir para um melhor desempenho destes novos agentes.

De forma mais concreta fizemos a análise da ação de mediadores que exerciam a sua função nos cursos EFA-NS (Educação e Formação de Adultos - Nível Secundário, destinados a adultos que pretendem adquirir o diploma relativo a este nível de ensino: $12^{\circ}$ ano de escolaridade). Tais cursos têm uma equipa pedagógica' composta pelos formadores de cada curso e por um mediador. Este de acordo com o Documento editado pela Agência Nacional Para a Qualificação, que enquadra institucionalmente a oferta educativa em análise, "deverá ser detentor de habilitação académica de nível superior e formação específica para o desempenho desta função ou ter experiência relevante no trabalho com adultos, designadamente na utilização da metodologia de Balanço de Competências e nas abordagens autobiográficas" (Gomes \& Rodrigues, 2007, p. 54).

O mediador, de acordo com a Portaria 230/2008, de 7 de março, possui as seguintes atribuições: intervir no processo de recrutamento e seleção dos adultos, colaborando com o representante da entidade formadora na constituição dos grupos de formação; assegurar o acompanhamento e orientação pessoal, social e pedagógica dos adultos; assegurar a articulação entre as partes envolvidas, como intermediário privilegiado entre a equipa formativa e o grupo de formandos, e entre estes e a entidade formadora; e coordenar a equipa pedagógica no processo formativo.

E se nestas atribuições legais do mediador estão, na nossa perspetiva, dimensões claras de supervisão pedagógica, a própria função de mediação em geral está sempre presente, de acordo com Samuel Gento-Palacios (2004), na atuação de um supervisor, pois este aparece numa posição intermédia, resolvendo problemas entre escolas e administração educativa e entre órgãos de gestão da escola e professores, ou seja, entre equipas. O supervisor medeia entre a lei e os contextos reais pois a primeira função do supervisor é fazer cumprir a lei; medeia no sentido de negociar diretamente, uma vez que pode participar em situações de negociação e representar a administração escolar frente à outra parte; medeia porque arbitra em duas matizes, sendo a primeira a arbitragem da autoridade hierárquica em contextos profissionais e administrativos e a segunda a arbitragem a pedido de uma das partes; medeia com vista a resolver conflitos,

1 Todos os Cursos EFA têm tais equipas pedagógicas. 
podendo ter vários papéis (Gento-Palacios, 2004). Pode ter o papel de simples moderador das intervenções das várias partes, o de intermediário, sobretudo nas negociações não presenciais e o de mediador propriamente dito porque conduz o processo.

O mediador dos cursos EFA tem assim, decorrente do que fomos referindo antes, um papel fundamental na prossecução desta modalidade educativa. Além de outras tarefas, é importante que assegure a supervisão e fomente o trabalho colaborativo da equipa que coordena. António Nóvoa (2007), ao referir-se ao caso dos professores em geral, alerta para a importância da colaboração ao defender que o conceito de educação permanente obriga os professores a investir na edificação de redes de trabalho grupal que sejam os alicerces de experiências de formação assentes na partilha e no diálogo profissional.

As equipas pedagógicas dos cursos EFA que ocorrem nas escolas são constituídas, conforme já dissemos, por mediadores e formadores, que são simultaneamente professores dessas escolas. Julgamos, por este motivo, que a adoção da forma de trabalhar acima referida facilitará o papel dos mediadores dos cursos. Na verdade, defendemos que se este trabalho colaborativo for assumido entre todos os membros das equipas pedagógicas dos cursos EFA elas podem constituir-se em comunidades de prática e aprendizagem (Wenger, 2001). Podendo, desta forma, assumir o objetivo comum de atingirem um fim coletivo que, no caso, é a promoção de uma educação e formação de adultos que responda aos reais interesses dos adultos que frequentam tais cursos. Por outro lado, os processos colaborativos nos locais de trabalho também se constituem como momentos de formação para quem neles participa e isto também é relevante para a atividade educativa e formativa que mediadores e formadores têm junto dos adultos em formação, pois, como refere Paulo Freire (1975), só forma quem é igualmente formado. Esta ideia não é válida apenas para os processos formativos e educativos que possam ocorrer entre os membros das equipas pedagógicas, mas também entre estes e os próprios formandos.

Foi, então, como enunciámos antes, com o objetivo de tentar perceber até que ponto os mediadores dos cursos EFA realizam, no âmbito das suas atribuições, a função de supervisão e de que forma tal função pode ter influência na oferta educativa em causa, que concretizámos uma investigação qualitativa na qual confrontámos o discurso dos mediadores com as suas práticas, através de um estudo de caso exploratório. Os participantes foram dois mediadores de dois cursos EFA, de nível secundário, um de percurso $B$ e outro de percurso $C$, de uma escola secundária/3 do distrito de Vila Real, situado no norte de Portugal. Os cursos de percurso B e $C$ integram, formandos que iniciaram o curso com formação equivalente, respetivamente, ao $10^{\circ}$ e ao $11^{\circ}$ anos de escolaridade ${ }^{2}$. O estudo de caso exploratório foi concretizado através de uma entrevista semiestruturada a cada um dos mediadores e da observação de duas reuniões de cada uma das equipas pedagógicas dos referidos cursos.

Começamos por nos referir a dois dos temas que fizeram parte do enquadramento teórico da nossa investigação, passando, de seguida, à metodologia utilizada e aos resultados obtidos e terminamos com algumas considerações finais que procuram problematizar a forma de atuação dos

2 Os Cursos EFA-NS possibilitam adquirir o diploma escolar de conclusão deste nível de ensino (o $12^{\circ}$ ano de escolaridade), conforme já elucidámos antes, e permitem três tipos de percursos: A, para adultos que iniciam a sua formação com o $9^{\circ}$ ano, ou equivalente, concluído; $B$, para adultos que iniciam a sua formação com o $10^{\circ}$ ano, ou equivalente, concluído; e $C$, para adultos que iniciam a sua formação com o $11^{\circ}$ ano, ou equivalente, concluído. 
mediadores em análise, que consideramos afastar-se em aspetos essenciais do seu papel de supervisores e, com isso, poderem estar a comprometer princípios inerentes ao funcionamento dos cursos EFA.

\section{O mediador dos cursos EFA}

O conceito de mediação, pelo apelo ao espírito colaborativo, ao respeito e à responsabilidade e nunca à tomada de soluções pela coação, aplica-se a vários domínios da vida social e tornou-se progressivamente mais importante na sociedade global, onde ocorrem conflitos gerados por causas indeterminadas, sendo, por isso, emergente a necessidade de diálogo e de comunicação (Oliveira, 2009). A mesma opinião é perfilhada por Catarina Morgado e Isabel Oliveira (2009) quando afirmam que, atualmente, o reconhecimento de mais direitos e de maior exigência no respeito por eles, originaram o aumento exponencial da conflitualidade e da complexidade com que se esta se manifesta.

Entendemos que a mediação, embora possa ser identificada em várias práticas, é essencialmente social e educativa e se é verdade, como vimos acima, que tem um importante papel para a coesão social, ela é sobretudo relevante para a transformação social e emancipação dos mais oprimidos através do papel que pode ter no processo a que Freire (1975) chamava de conscienciatização dos indivíduos e das comunidades a que estes pertencem.

Aqueles que desempenham o papel de mediadores podem desenvolver capacidades de respeito pelo outro, de comunicação assertiva, de aceitação da diferença relativamente à perceção da realidade (Morgado \& Oliveira, 2009) e ainda competências de trabalho cooperativo e de criatividade.

A função de mediador na área da educação de adultos, de acordo com Sandra Pratas Rodrigues (2009), deve ser exercida por formadores e outros profissionais, nomeadamente ligados às tarefas de orientação vocacional, portadores de habilitação de nível superior e com experiência significativa no campo da educação e formação de adultos.

Pensamos que o fator experiência de trabalho relevante no campo da educação e formação de adultos, aliado ao fator formação específica nesse mesmo campo, é essencial para o exercício do papel de mediador que se assuma como um promotor de uma educação problematizadora e libertadora, assente no processo de conscieciatização que procura a transformação daqueles que participam nos processos educativos em causa (Flecha, 1997; Freire, 1975).

As competências que se requerem ao mediador podem servir de exemplo aos formandos dos cursos EFA, uma vez que se pretende que, ao iniciarem o nível básico de educação, estes vão adquirindo "a capacidade de agir e reagir de forma apropriada perante situações mais ou menos complexas, através da mobilização e combinação de conhecimentos, atitudes e procedimentos pessoais, num contexto determinado, significativo e informado de valores" (Araújo, 2002, p. 9). Na nossa opinião isto ocorrerá tanto mais quanto maior for a consciência crítica desses formandos, e também dos mediadores e formadores dos cursos, ou seja, quanto maior for a perceção de todos os envolvidos da situação em que se encontram, do valor dos seus saberes e do que precisam fazer para transformar a sua realidade.

Ao mediador dos cursos EFA, de nível secundário, compete, de acordo com a Portaria 817/2007, de 27 de julho, colaborar com o representante da entidade formadora na constituição dos grupos de formandos; acompanhar e orientar os formandos em termos pessoais, sociais e pedagógicos; coordenar a equipa técnico-pedagógica no que concerne ao processo 
formativo, tendo sempre em atenção o cumprimento dos percursos individuais e do grupo de formandos; e assegurar a articulação entre a equipa técnico-pedagógica e os formandos e a de todos estes com a entidade formadora.

Quanto à constituição dos grupos de formação, e nos percursos tipificados, o mediador dinamiza a ocasião do diagnóstico, no qual analisa e define o perfil de cada formando para os integrar adequadamente nos grupos de formação; no que diz respeito aos percursos de nível secundário, analisa as habilitações escolares dos candidatos e a sua correspondência aos percursos tipificados. Relativamente à coordenação das metodologias de trabalho da equipa pedagógica é importante o mediador: fazer cumprir os percursos formativos, respeitando o desenho curricular e tendo em atenção as características do grupo de formação e de cada formando em particular; fomentar a articulação entre as áreas de competências-chave e entre as componentes de formação, no caso dos cursos de dupla certificação; e dinamizar reuniões de trabalho com vista a planear atividades integradoras, momentos de avaliação e métodos para a sua obtenção. Articula com o representante da entidade formadora com o fim de acautelar as condições necessárias para a realização das distintas atividades e estratégias. Relativamente ao acompanhamento e orientação dos formandos, função que maior dedicação exige por parte do mediador e muito importante para o sucesso das aprendizagens, o mediador tem de ter consciência de que os formandos, sobretudo os do nível básico, são pessoas inseridas em contextos complexos (Rodrigues, 2009).

O mediador tem ainda o importante papel de favorecer a inclusão dos formandos e conhecer em profundidade todas as matrizes que se entrelaçam na edificação de um percurso EFA: a matriz concetual do modelo de formação; as experiências e as motivações de vida dos adultos, ou seja, a matriz experiencial; e a matriz sociocultural, onde os adultos se inserem e desenvolvem os seus vários trajetos. O mediador é formador, no nível secundário, na área de Portefólio Reflexivo das Aprendizagens (PRA) que, devido às suas características e metodologia, se enquadra perfeitamente no seu perfil.

\section{A supervisão}

O conceito de supervisão é polissémico, sendo várias as perspetivas e definições partilhadas por diferentes autores. Esta diversidade de significados atribuídos à supervisão está associada ao facto do conceito ter subjacente uma determinada conceção de sociedade, cultura, administração pública, filosofia educativa, políticas educativas, teorias e conceções de escola e de formação de professores (Neves, 2007). Assim, a forma como a supervisão é percecionada tem vindo a modificar-se ao longo dos tempos, e a realidade portuguesa não tem sido exceção.

Segundo Isabel Alarcão e José Tavares (2003), na década de oitenta do século $X X$, as funções da supervisão cingiam-se ao acompanhamento dos estágios iniciais de professores e não existia formação em supervisão, tendo os profissionais e os supervisores conscientes e empenhados nas suas obrigações de fazer formação a título individual. Neste contexto, a supervisão é encarada como "o processo em que um professor, em princípio mais experiente e mais informado, orienta um outro professor ou candidato a professor no seu desenvolvimento humano e profissional" (Alarcão \& Tavares, 2003, p. 16). Trata-se de um processo, porque acontece num tempo continuado, tem um propósito, que é o desenvolvimento profissional do professor e situa-se no espaço da orientação de uma atividade profissional. Idália Sá-Chaves (1997) considera a supervisão como um conjunto de saberes interligados de forma organizada, um todo sistemático, cujas características de totalidade são conferidas pela sua racionalidade intrínseca.

De acordo com Donald A. Schön (1987), a qualidade da supervisão avalia-se pela maior ou menor capacidade do supervisor em criar condições que possibilitem uma reflexão crítica sobre a ação profissional. É fundamental que o supervisor crie uma atmosfera propícia à aprendizagem, promova situações de experimentação e reflexão e ainda adopte uma postura de crítica construtiva no que diz respeito à atuação do professor em formação, uma vez que o supervisor é o facilitador da aprendizagem do professor (Schön, 1983).

Nos anos noventa do século $X X$, assistiu-se a uma viragem na concetualização dos modelos de formação de professores e, simultaneamente, a uma mudança de paradigmas concetuais na forma de ver o exercício da supervisão e o papel do supervisor. Em Portugal, a supervisão conheceu desde essa altura um grande desenvolvimento, para o qual em muito contribuiu a criação de cursos de especialização e de mestrado nesta área. Em simultâneo, esse desenvolvimento permitiu a clarificação e desmistificação do termo, no sentido da sua melhor aceitação, apesar de continuar a suscitar reações negativas relativamente à sua utilização, por permanecer conotado com atitudes de chefia, autoridade e imposição (Vieira, 1993).

Este desenvolvimento do conceito conduz a que, para além de incluir uma dimensão auto-reflexiva e autoformativa, a supervisão passe a ser encarada não numa perspetiva individual mas na centralidade da escola. Ou seja, atualmente, a supervisão é entendida como uma atividade que pretende o desenvolvimento 
e a aprendizagem dos profissionais, processos que não se resumem ao contexto da sala de aula mas que se estendem ao contexto escolar (Alarcão \& Tavares, 2003).

O desenvolvimento profissional e pessoal dos professores reveste-se de dimensões que valorizam os processos de auto-reflexão e autoconsciencialização e o supervisor é percebido como um "ecologista social" que reconhece e valoriza os contextos nas aprendizagens (Neves, 2007). Neste sentido, é fundamental que a supervisão assente numa "visão de qualidade, inteligente, responsável, livre, experiencial, acolhedora, empática, serena e envolvente de quem vê o que se passou antes, o que se passa durante e o que se passará depois, ou seja, de quem entra no processo para o compreender por fora e por dentro" (Henry Mintzberg, 1995, citado em Alarcão \& Tavares, 2003, p. 45).

Olhando para o desenvolvimento do percurso da supervisão pedagógica, apercebemo-nos de um alargamento da sua área de influência. Deixa de estar centrada na sala de aula e na formação inicial e aparece associada ao desenvolvimento profissional, sobretudo daqueles que são já profissionais e se encontram em ambiente de formação contínua em contexto de trabalho, com uma orientação mais colaborativa e menos hierárquica. Presentemente, a supervisão tem também como função a dinamização e o acompanhamento do desenvolvimento da escola no sentido de contribuir para que ela se possa tornar numa instituição aprendente (Senge, 2002). Não se ocupa apenas dos professores em formação inicial, mas de toda a escola e de todos os que aí ensinam, estudam ou ajudam na função educativa (Alarcão, 2009).

\section{Metodologia}

O estudo que concretizámos pretendeu responder à seguinte questão de partida:

- O mediador dos Cursos EFA, de Nível Secundário, exerce as funções supervisivas formalmente inerentes ao seu cargo e de que forma o faz?

Com vista a dar resposta a tal questão, formulámos os seguintes objectivos:

- Investigar, a partir da análise de documentos legais, o papel supervisivo inerente à função de mediador dos Cursos EFA, de Nível Secundário.

- Inferir, a partir da análise do discurso e da prática dos mediadores, se e de que forma concebem e exercem o seu papel enquanto supervisores.

- Analisar congruências e incongruências entre o discurso dos mediadores, a sua prática e a legislação que a regulamenta.

A investigação que realizámos pode ser entendida como um estudo de caso exploratório. O estudo de caso, segundo Sharan B. Merriam (1988), em Robert Bogdan e Sari Biklen (1994), consiste na observação pormenorizada de um indivíduo ou de um contexto, de um determinado acontecimento ou de apenas uma fonte de documentos. Segundo Alberto B. Sousa (2005), a grande vantagem deste tipo de estudo é permitir a centralização das atenções do investigador e a aplicação cruzada de vários instrumentos de avaliação sobre um caso, identificando os diferentes 
processos interactivos em execução. Permite ainda que um caso seja estudado em pouco tempo ou em maior tempo, fazendo o acompanhamento da sua evolução. Este tipo de estudo assenta em três procedimentos: a recolha de dados, o mais exaustiva possível; a análise desses dados, qualitativa e/ou quantitativa, buscando-se constantes ligações, diferenças, frequências e elementos de valor com significado relevante; e a realização de inferências partindo da análise e o retirar de conclusões.

Pareceu-nos então que este método de investigação se afigurava como mais ajustado para alcançarmos o objetivo a que nos propusemos, pois pretendíamos realizar uma investigação em profundidade que nos permitisse entender o nosso objeto de estudo, por outro lado disponhamos de tempo e de outros recursos limitados para a concretização da pesquisa de campo. O nosso estudo de caso reporta-se à função supervisiva de dois mediadores, no exercício do seu cargo, de dois Cursos EFA-NS, de uma escola secundária/3 do distrito de Vila Real (norte de Portugal), um de percurso $B$ e outro de percurso $C$, em consonância com as competências determinadas pelos normativos legais. Estes mediadores serão designados, respetivamente, por mediador $\mathrm{A}$ e mediador $\mathrm{B}$.

Estes mediadores têm perfis muito semelhantes. Ambos são do género masculino. O mediador A tem 43 anos de idade possui uma licenciatura na área da Ciências Sociais e Humanas, exerce a função de professor do ensino secundário há 18 anos, tem alguma experiência de ensino de pessoas adultas (lecionou quatro anos no ensino recorrente) e frequentou uma ação de formação de 20 horas sobre mediação nos cursos EFA. O mediador B tem 44 anos, é igualmente licenciado na área da Ciências Sociais e Humanas, é professor do ensino secundário há 21 anos, tem também alguma experiência no ensino de adultos (lecionou 5 anos no ensino recorrente) e já tinha exercido a função de mediador e formador nos cursos EFA durante um ano, mas nunca frequentou ações de formação sobre mediação.

$\mathrm{O}$ estudo foi efectuado com recurso à recolha e análise de documentos legais que enquadram a função de supervisão dos mediadores dos cursos EFA, a uma entrevista semiestruturada (Sousa, 2005), realizada a cada um dos mediadores, e à observação de duas reuniões de cada uma das equipas pedagógicas de cada curso. Este tipo de entrevista utiliza-se nas ocasiões em que é preciso investigar profundamente uma certa situação vivida em condições muito concretas, como foi o caso estudado.

As entrevistas foram marcadas atendendo à disponibilidade dos entrevistados. Foram realizadas no espaço escolar, numa pequena sala, fazendo-se munir a investigadora que esteve no terreno, de um guião com as questões que interessava que o sujeito desenvolvesse. Anteriormente, os entrevistados tinham sido informados sobre a essência da investigação e indagados quanto à sua disponibilidade para colaborar no estudo. Posteriormente a esta primeira abordagem foi marcada a data, a hora e o local da realização das entrevistas e apresentados os objetivos da mesma. Para o registo das entrevistas, recorreu-se à sua gravação para, posteriormente e após a sua audição repetida, se fazer a análise de conteúdo (Sousa, 2005).

No que diz respeito à observação efetuada recorreu-se às seguintes modalidades: estruturada porque houve a preocupação de rigor no registo das ações que interessava observar; participante e natural pois a investigadora que esteve no terreno exerce a sua atividade profissional na mesma comunidade das pessoas observadas e nos cursos EFA; sistematizada, uma vez que o problema estava bem determinado; individual porque havia apenas um observador no campo; em campo pois as observações aconteceram no local onde decorriam as reuniões (Sousa, 2005).

A observação das duas reuniões de cada equipa pedagógica de cada um dos cursos, presididas pelos mediadores em estudo, foram audiogravadas. Quanto ao mediador da turma de percurso $B$, observámos reuniões relativas a seis núcleos geradores ${ }^{3}$. No que concerne ao mediador da turma de percurso C, observámos reuniões relativas igualmente a seis núcleos geradores, que correspondem neste caso a todo o percurso formativo.

A técnica utilizada para interpretar os dados foi a análise de conteúdo. De acordo com Laurence Bardin (1977, p. 42), pertencem à análise de conteúdo "todas as iniciativas que, a partir de um conjunto de técnicas parciais mas complementares, consistam na explicitação e na expressão desse conteúdo, com o contributo de índices passíveis ou não de quantificação, a partir de um conjunto de técnicas, que embora parciais, são complementares".

No nosso caso, e depois de transcrevermos as audiogravações das entrevistas realizadas aos mediadores e das reuniões das equipas pedagógicas a que assistimos, realizámos uma leitura global e flutuante das referidas transcrições com o propósito de contatar com os documentos e conhecer o texto, permitindo a invasão de impressões e orientações (Bardin, 1977), e de nos inserirmos o mais possível na linha de pensamento de cada um dos intervenientes do estudo.

A etapa seguinte consistiu na categorização, previamente estabelecida e de acordo com a função dos mediadores EFA-NS expressa nos normativos legais de dinamização da equipa pedagógica e na selecção

3 Temas abrangentes a partir dos quais se podem criar e evidenciar competências-chave. 
de unidades de registo. A categorização consiste na classificação, por diferenciação primeiramente e depois por reagrupamento de elementos que constituem um conjunto (Bardin, 1977).

Segundo Jorge Vala (1986) as unidades de registo são grupos de dados com características análogas que podem ser estabelecidas imediatamente, durante o decorrer do processo de análise ou coincidir nos dois processos, sendo a sua seleção e identificação a tarefa que levanta mais dificuldades de operacionalização.

No nosso estudo e no caso das entrevistas utilizámos duas categorias, cada qual com subcategorias: a categoria Perspetivas do Mediador Sobre a Supervisão, que teve como subcategorias o Conceito de Supervisão e a Existência de Práticas de Supervisão Inerentes ao Papel de Mediador; e a categoria Dinamização da Equipa Pedagógica no Âmbito do Processo Formativo, que teve como subcategorias os Modos de Dinamização, os Mecanismos de Apoio Desenvolvidos com os Formadores, a Periodicidade das Reuniões, o Tipo de Problemas mais Frequentes, as Atitudes Tomadas Perante os Problemas, a Intervenção do Mediador na Definição do Desenho Global e da Construção Curricular, o Trabalho nas Reuniões de Planificação, a Partilha de Saberes e Materiais, a Reflexão sobre as Estratégias Adotadas, as Formas de Atuação relativamente à Verificação do Trabalho Efetuado, os Procedimentos Postos em Prática em caso de Desajustamentos, e as Alterações na Rotina. No caso das reuniões utilizámos a segunda categoria (Dinamização da Equipa Pedagógica no Âmbito do Processo Formativo) e respetivas subcategorias acima referida para as entrevistas.

\section{Resultados: análise comparativa do discurso e da prática dos mediadores}

Os dois mediadores concordam com a existência de práticas de supervisão inerentes ao cargo que desempenham, embora não se refiram a todas as situações em que monitorizam esta ação. O conceito de supervisão apresentado pelo mediador A faz supor que este não possuiu uma noção clara do mesmo. Por sua vez, o mediador B revela possuir maior clareza e profundidade das funções que o conceito implica. A sua perceção mostra alguma tendência de aproximação a Flávia Vieira (1993), quando a autora expressa que a supervisão se define como uma monitorização sistemática da prática pedagógica, enfatizando processos reflexivos e de experimentação, e com Isabel Alarcão (2009), uma vez que esta autora aponta que a supervisão deve ter influência na melhoria do ensino e da aprendizagem, pretendendo-se chegar aos discentes através do docente.

A supervisão implica um conhecimento que alguém deve ter sobre todos os agentes e intervenientes num determinado processo. Isto dito de uma forma sintética (entrevista Mediador A).

Regulação de processos de ensino-aprendizagem, sendo a educação um objeto de formação e investigação na interação entre pensamento e ação (entrevista Mediador B).

No que concerne ao papel supervisivo do mediador na dinamização das equipas de formadores e comparando os seus discursos com as suas práticas, encontrámos congruências e incongruências. Alguns aspetos não foram passíveis de comparação porque não foram observados nas reuniões, estando apenas ao nosso dispor os discursos.

As congruências, subjacentes aos dois mediadores, reportam-se à utilização do correio eletrónico como meio de contacto entre os membros 
das equipas pedagógicas, à prestação de informações, à elaboração antecipada e individual das planificações e abertura e incentivo a que nas reuniões da equipa houvesse partilha de sugestões e pontos de vista, como se pode verificar nos excertos das entrevistas e discursos dos mediadores nas reuniões das equipas pedagógicas observadas:

Sempre que se justificar, reunimos. Mas agora nós utilizamos muito as TIC, portanto, são assim evitadas muitas reuniões (entrevista Mediador A).

Atenção, nesta altura não há muitos painéis disponíveis. Vou ver o que se consegue e depois aviso por mail. Ficamos hoje por aqui (Mediador B, $2^{\mathrm{a}}$ reunião).

Presto-Ihes toda a ajuda necessária. Se não souber, tento informar-me junto de outras entidades dentro ou fora da escola ou pesquiso informação sobre o assunto. Se precisarem de materiais, disponibilizo o que tenho ou entro em contacto com outros colegas. Todos os meus contactos, telefónicos e correio eletrónico, estão disponíveis para todos os formadores (entrevista Mediador B).

Em primeiro lugar, procuro sempre que as pessoas, à partida, apresentem as suas opiniões, as suas ideias, tragam os seus contributos. Mas, a experiência em situações semelhantes disse-me que o mediador deve trazer o trabalhinho já feito de casa ou grande parte dele. O mediador tem que trazer já muita coisa pré-concebida e já estruturada. Depois das outras pessoas falarem, depois das outras pessoas darem os seus contributos, que normalmente geram alguma confusão e fica tudo no ar, é preciso sempre alguém que organize e sintetize as propostas da equipa (entrevista Mediador A).

Elaborado por mim e depois colocado à disposição da equipa pedagógica para alterações, penso que essa será uma das formas de minimizar alguns problemas que eventualmente possam vir a surgir no seio da equipa pedagógica (entrevista Mediador B).

Bom, seguidamente, vou distribuir os documentos que fazem um bocadinho a síntese do desenho global já feito anteriormente e que eu sintetizei agora com a atualização de tempos, com os documentos relativos ao tema-problema, que nós iremos definir, assim como a atividade integradora para estes núcleos e depois uma folha onde constará a planificação que vocês irão rever ou construir nas vossas áreas de competência (Mediador A, $1^{\text {a }}$ reunião).

Os mediadores revelam, nos seus discursos, disponibilizar informação aos formadores, o que está de acordo com Flávia Vieira (1993) quando refere que a função primordial do supervisor é fornecer informação, relevante e atualizada, uma vez que ser uma pessoa informada é essencial no processo de supervisão.

A intervenção dos mediadores na definição do desenho global e da construção curricular dos cursos que medeiam é primordial, uma vez que uma das suas funções é fazer cumprir os percursos formativos, respeitando o desenho curricular dos mesmos, promovendo a articulação entre as áreas de competências-chave e dinamizando sessões de trabalho em equipa pedagógica vocacionadas para as tarefas de planificação (Rodrigues, 2009). O mediador A justifica a sua atuação com base em experiências anteriores, assumindo-se como organizador e sintetizador das propostas dos membros da sua equipa. O mediador B crê que a sua atuação pode ser uma mais-valia junto da equipa pedagógica, no sentido de minorar problemas que possam vir a surgir no seio desta, assumindo a sua função como mediador com vista a garantir a interlocução entre todos. Esta perspetiva é referida por Sandra Pratas Rodrigues (2009, p. 50) quando afirma: "todos 
os elementos da equipa têm como responsabilidade a participação ativa em momentos especificamente destinados a um conjunto de tarefas comuns a todos eles".

As incongruências registaram-se, no que concerne ao mediador A, nos aspectos que abaixo apresentamos. Na entrevista, o mediador afirmou que nas reuniões contribui para que os formadores implementem estratégias adequadas com vista ao sucesso dos formandos:

Procuro dinamizar sempre em todas as situações que o exijam. Como? Reunindo com eles, procurando informá-los de tudo aquilo que diz respeito aos formandos, no fundo, contribuir para que os formadores possam desenvolver uma pedagogia adequada que facilite o sucesso dos formandos (entrevista Mediador A).

Como já referi anteriormente, eu trago as sugestões, apresento-as depois ponho-as à discussão, se for preciso alterar alguma coisa, altera-se. Nas reuniões, as características individuais de cada formando são sempre evidenciadas. Eu, como mediador, forneço a informação que tenho acerca de cada um para que possa haver melhor entendimento das situações (entrevista Mediador A).

De acordo com o que observámos em tais reuniões, esta situação não nos pareceu acontecer, uma vez que o mediador nunca se referiu no seu decorrer à adequação de estratégias ou atividades com esse objetivo.

O seu discurso apontou para a colaboração entre toda a equipa pedagógica, para o diálogo e confronto de ideias em todas as situações relacionadas com os formandos e com o desenvolvimento do curso. No entanto, as suas práticas fazem-nos crer que se revelou menos colaborativo e aberto à discussão e apresentação de outras perspectivas. O mediador declarou que a sua equipa planifica em conjunto, no entanto, pelo que nos foi possível observar, as planificações específicas de cada área de competências-chave são feitas individualmente e não são posteriormente discutidas em grupo, mas enviadas por correio eletrónico para o mediador, impossibilitando esta prática o trabalho cooperativo:

Eu vou dar-vos um guia de orientação para depois vocês fazerem as planificações específicas. Se estiverem de acordo utilizam, caso contrário modificam. Quando estiverem prontas, enviam-me por mail (Medidor A, $2^{\text {a reunião). }}$

O mediador afasta-se do princípio de integração pretendido para a equipa pedagógica, uma vez que, de acordo com as suas orientações, cada área fará a sua planificação específica, que lhe será posteriormente enviada por correio eletrónico. Tudo isto acontece sem lugar à discussão e análise colaborativa em equipa. Carl D. Glickman (1985), citado por Isabel Alarcão e José Tavares (2003), refere que o realce dado a determinadas atitudes determina o estilo de supervisão adotado.

O mediador afirmou que a sua equipa considera sempre as características individuais de cada formando e do grupo de formação quando as suas práticas não nos fizeram chegar a essa conclusão. Na verdade, o mediador, nas reuniões a que assistimos, nunca apresentou uma caracterização dos formandos em particular nem do grupo de formação:

E qual seria o tema? Eu pensei alguma coisa, mas não quer dizer que seja isto, é uma questão de falarmos, discutirmos e chegarmos a conclusões. Quando olhei para os núcleos, em termos de tecnologias, ocorreu-me logo a Internet e, relativamente ao tema -problema: os perigos da Internet. E como questões geradoras pensei nas seguintes: será que a Internet tem desvantagens? Como evitar ser vítima dos perigos da Internet? (Mediador A, $2^{a}$ reunião).

Ora, o Referencial de Competências-Chave para o nível secundário tem implícita "a noção da absoluta centralidade do percurso singular de cada adulto. Por isso, as situações de vida do adulto constituem o ponto de partida e motor da desocultação, evidenciação e validação das competências; elas constituem igualmente o motor do desenvolvimento dos percursos formativos assentes em competências-chave" (Gomes, 2006, p. 19).

No seu discurso, o mediador fez-nos pensar que incentivou os formadores que integraram a equipa pedagógica a darem, mais tarde, novos contributos para o desenvolvimento do curso, como se pode ver pelo excerto da sua entrevista, no entanto, nas reuniões que observámos tal situação não se verificou:

A integração de novos elementos traz sempre alguma alteração ao funcionamento da equipa. Claro que informei as pessoas que chegaram sobre a forma como o curso estava a decorrer e procurei que os novos formadores trouxessem outros contributos. Procurou-se articular toda a informação que existia com a nova e conseguiu-se isso perfeitamente (entrevista Mediador A).

No que respeita ao mediador $B$, as incongruências entre discurso e prática foram encontradas nos aspetos que passamos a descrever.

Relativamente à existência de colaboração entre todos os membros da equipa pedagógica, o mediador afirma, no seu discurso, que ela existe, mas, pelo que observámos, não nos pareceu uma prática frequente. Exemplos da ausência de um verdadeiro trabalho 
conjunto e colaborativo tornam-se evidentes com a menção do mediador às reuniões por áreas de competências-chave, o envio das planificações específicas via correio eletrónico e ainda quando salientou que uma visita de estudo se destinava apenas à área de Cidadania e Profissionalidade:

Agora, os formadores de cada área reúnem e fazem a sua planificação específica e depois enviam, ok? (Mediador B, $1^{\text {a }}$ reunião).

Vamos continuar com a planificação. Na descrição geral das atividades, mantemos interpretação de esquemas e gráficos, observação e descrição de situações e problemas, visitas de estudo? Visita ao Museu da Vila Velha e Arqueologia e Numismática? Mas isto é só para Cidadania e Profissionalidade, não é? (Mediador B, $2^{a}$ reunião).

A perspetiva integradora está subjacente ao Referencial de Competências-Chave para o nível secundário e "supõe a existência de uma forte interação das diferentes Áreas, já que o domínio de competências específicas de cada uma delas enriquece e facilita a aquisição de outras, reconhecendo-se que algumas competências são comuns às diferentes Áreas, resultantes da visão de transversalidade transmitida pela noção de competências-chave" (Gomes, 2006, p. 18). Ora, no nosso estudo isto parece não ter ocorrido.

No seu discurso, o mediador referiu que as características individuais dos formandos e do grupo são tidas em consideração na elaboração das planificações, referindo inclusivamente que estas devem ser adaptadas a essas mesmas características. Contudo, nas reuniões observadas, não foi por nós registada esta prática. Revelou, no entanto, alguma preocupação na diversificação das atividades e dos materiais usados:

Alguns formandos não evidenciam tantas competências como outros, então é necessário adaptar os materiais ao tipo de aluno, servindo em simultâneo para todos (entrevista Mediador B).

Isso não é problema nenhum. As horas são as mesmas, 50, para cada área, temos é mais actividades e menos horas dentro da sala de aula. Mas os formandos preferem a variedade. E olha que aprendem muito mais do que se estiverem sempre a fazer fichas (Mediador $B, 2^{a}$ reunião).

Maria do Carmo Gomes e Sandra Rodrigues (2007) asseguram que os cursos EFA-NS regem-se por princípios de pluralidade e diversidade e, como tal, o desenho curricular de base deve concretizar-se numa pluralidade de percursos formativos, adaptados aos diferentes perfis dos formandos, o que origina que estes trabalhem segundo metodologias de diferenciação pedagógica. Uma vez mais não parece ser o que acontece no caso por nós observado.

Na entrevista, o mediador declarou que existe reflexão sobre as estratégias adotadas por cada formador e mediador no decorrer do processo formativo, mas nas reuniões observadas a reflexão a esse nível não foi detetada. Apenas se centrou na seleção do tema-problema:

Sim. Essas reflexões são importantes para se ter a noção do que é necessário alterar para um melhor processo de evidência de competências (entrevista, Mediador B).

Relativamente ao curso anterior, vamos mudar o tema-problema? (...) Assim sendo, a actividade integradora fica então a produção de um DVD, com o título: "A energia nuclear - prós e contras" (Mediador B, $2^{\mathrm{a}}$ reunião). 
A reflexão na e sobre a prática é um processo de desenvolvimento profissional (Schön, 1987). Os formadores deveriam refletir isoladamente sobre a forma como formam, os resultados obtidos e aquilo que precisam de melhorar, devendo esta reflexão isolada ser continuada numa reflexão conjunta com os seus parceiros.

O mediador afirmou que surgiram pequenos problemas pontuais no decorrer do seu curso em termos da equipa pedagógica que, no entanto, nós encaramos como um aspeto potencialmente positivo dado que é nossa perceção que a sua ocorrência é motivada pela possibilidade de haver algum confronto de ideias. O excerto da entrevista e o episódio observado e aqui relatado remetem para as tais situações problema:

Houve, claro. Teve de haver mais partilha, mais interação. Não houve grandes problemas. Dois formadores tiveram mais dificuldades de adaptação e de trabalho conjunto, mas um dos elementos cedeu e as coisas foram funcionado (entrevista Mediador B).

\section{Episódio}

Med: $H$, estás muito calado. Diz da tua justiça.

Formador 2 CLC: Para CLC, vai ser muito difícil trabalhar este tema.

Med: Mas diz então. Sabes que nós estamos aqui para discutir o assunto.

Formador 2 CP: Ora, diz-nos lá quais são os teus domínios de referência para ajudarmos (...)

Med: Falta a terceira questão.

Formador 2 CLC: Atenção, não se esqueçam, tem que ser uma que abarque todas as áreas, caso contrário vai ser muito difícil CLC trabalhar este tema. Formador 2 STC: "Portugal deve apostar na energia nuclear?"

Formador 1 STC: Ou "A energia nuclear será uma aposta segura?"

Formador 1 CP: Mas aqui já estás a centralizar mais a questão.

Formador 2 STC: Mas podemos pôr "Que energias para o futuro?"

Formador 1CP: Acho melhor, já não se centraliza tanto.

Formador 1 STC: O problema é que há poucas sessões (...).

Med: Isso não é problema nenhum. As horas são as mesmas, 50, para cada área, temos é mais actividades e menos horas dentro da sala de aula. Mas os formandos preferem variar do que estar sempre a fazer fichas, e assim aprendem mais (Mediador $B, 2^{a}$ reunião).

Estas situações problemáticas da prática podem ser fonte de discussões educativas, no sentido de as equipas pedagógicas procurarem ultrapassar tais problemas através da inserção de novos recursos na sua prática, aumentando e refazendo, desta forma, o reportório coletivo dessas mesmas equipas (Loureiro, 2010). No entanto, não nos pareceu, pelos dados recolhidos, que no caso estudado essa maneira de trabalhar estivesse implementada.

Estes foram alguns dos principais resultados a que chegámos acerca do discurso e da prática daqueles dois mediadores dos cursos EFA-NS, que nos mostram a existência de diferenças significativas entre uma realidade e outra em aspetos muito relevantes para o funcionamento desejável deste tipo de ofertas educativas de adultos.

\section{Conclusões}

Estamos cientes das limitações que um estudo de caso contém. Uma vez que se resume a um estudo restringido a uma determinada realidade, os resultados a que chega não poderão ser, por si, generalizáveis. Poderão 
representar um modesto contributo que poderá ser acrescentado a outros estudos já feitos ou a desenvolver futuramente, ligados à mesma temática. Alberto B. Sousa (2005) confirma que este método apresenta desvantagens. Estas situam-se ao nível da impossibilidade do estabelecimento de generalizações, como já referimos. Torna-se também difícil realizar verificações sobre as informações obtidas pois trata-se de uma investigação no local e no momento. No entanto, para Robert K. Yin (2005), o estudo de caso continua a ser um dos mais desafiadores de todos os esforços das ciências sociais e apresenta as vantagens a que já nos referimos na secção da metodologia.

Assim, pensamos que a pesquisa que realizámos, apesar das suas limitações, pois tratou-se de um estudo de caso exploratório a necessitar de maior aprofundamento, permite-nos terminar reforçando a ideia de que encontrámos incongruências entre os discursos e as práticas dos participantes neste estudo, o que nos leva a defender que as funções supervisivas dos mediadores estudados, inferidas dos Decretos-Lei 115-A/98, de 4 de maio e 75/2008, de 22 de abril, estão mais presentes nos seus discursos do que nas suas práticas.

Nas reuniões das equipas pedagógicas a que assistimos, não foi observada a salvaguarda das características de cada formando e do grupo de formação e a análise das suas necessidades e dificuldades, aquando da planificação dos núcleos geradores. A nosso ver, não foram proporcionados, de forma consciente e planificada, momentos de reflexão sobre a prática profissional de cada formador, sobre a análise das dificuldades ou competências dos seus formandos e sobre a planificação de estratégias de atuação para serem desenvolvidas de forma colaborativa. Estes aspetos muito importantes foram, no entanto, referidos pelos mediadores nos seus discursos.

Ora, as práticas reflexivas e colaborativas, segundo a nossa perspetiva, são uma dimensão essencial no trabalho das equipas pedagógicas dos cursos EFA-NS, coordenadas pelos mediadores, uma vez que estes são formadores, nas turmas onde exercem a mediação, da área de PRA, e os seus formandos, nas diferentes áreas que integram o Referencial de Competências-Chave, devem ir desenvolvendo um portefólio de caráter reflexivo, de acordo com a Portaria 817/2007, de 27 de julho. É justamente este caráter reflexivo que, na opinião de Márcia Barbosa Aguiar (2009), diferencia este portefólio de outros tipos de portefólio. Este é ainda o resultado de um processo de formação em que o adulto participa ativamente na seleção do seu conteúdo e na definição dos critérios para avaliar o mérito do seu desempenho, mas orientado nas suas escolhas e nas suas reflexões pela equipa formativa, numa postura de colaboração, sempre presente na construção do PRA. Pensamos, por estes motivos, que reflexão e colaboração são ações transversais imprescindíveis aos cursos EFA.

Se o mediador destes cursos não implementa esta forma de trabalhar junto de formadores e formandos dificilmente conseguirá contribuir para a conscienciatização de todos os adultos presentes no processo educativo (Freire, 1975) e, quando muito, será um mediador que resolve conflitos, que contribui para a existência de uma certa coesão no grupo, mas não será, certamente, um mediador que contribua para a transformação social de todos e em particular dos adultos em formação, afastando-se, desta forma, do principal papel da educação e formação de adultos (Finger, 2008).

Os resultados deste nosso estudo vão no sentido de outros realizados na mesma área geográfica acerca das práticas educativas de adultos de organizações não-governamentais de desenvolvimento local (Loureiro, 2008), pois tal como aí também a atual pesquisa nos leva a pensar na possibilidade de que a educação de adultos concretizada pode afastar-se de alguns dos princípios orientadores dos cursos EFA.

Perante os dados obtidos, parece-nos ser importante, como possíveis formas de superação das contradições encontradas entre discurso e prática, que os mediadores, como figuras centrais de um curso EFA-NS, adquiram formação específica e contínua na área da supervisão, uma vez que, de acordo com Alarcão e Tavares (2003), todos e cada um deve exercer funções de auto e hetero-supervisão, e, claro está, adquiram também uma formação mais sólida e contínua na área da educação e formação de adultos. Consideramos ainda ser relevante que os mediadores se tornem verdadeiros líderes de comunidades de prática e de aprendizagem, neste caso da equipa pedagógica do curso que medeiam, provocando no seu seio a discussão, o confronto de ideias, fomentando e rentabilizando a reflexão e a aprendizagem em colaboração, auxiliando a organizar o pensamento e a ação, contribuindo, dessa forma, para o desenvolvimento profissional contínuo de quem com eles trabalha e, dessa forma, também para a tomada de consciência crítica dos adultos em formação.

De acordo com Alarcão e Tavares (2003) é importante que o supervisor crie condições propícias ao trabalho e à interação, facilite a reflexão, desenvolva o espírito reflexivo, o autoconhecimento, inovador e colaborativo, ajudando a identificar e a resolver problemas e dificuldades, a determinar os aspetos que devem ser observados para posterior reflexão e estabelecimento de estratégias adequadas, a planificar e avaliar o processo educativo, a definir planos de ação e a criar espírito profissional.

Julgamos que com esta forma de trabalhar estas ofertas educativas estariam realmente mais próximas 
dos adultos. Na verdade, tal maneira de trabalhar permitirá uma maior capacidade de reflexão dos seus membros na e sobre a prática (Schön, 1987) e com isso a existência de uma maior possibilidade de não se fazer um "uso mecânico de determinados sistemas especializados de conhecimento" abstracto (Loureiro, 2008, p. 236), nos quais assentam os modelos destas ofertas educativas.

Por fim, acreditamos que estudos como o que concretizámos acerca da execução das funções de supervisão inerentes ao papel dos mediadores dos cursos EFA podem ser um contributo para um melhor desempenho destes novos agentes do campo da educação de adultos. Como vimos, no caso pesquisado, os mediadores atuam de uma forma tendencialmente empírica e o exercício da sua função de supervisão está mais presente nos seus discursos do que nas suas práticas. Tal facto pode comprometer este tipo de ofertas educativas. Pelo contrário, uma prática dos mediadores assente numa supervisão reflexiva pode fazer com que tais ofertas educativas se aproximem mais dos reais interesses dos adultos que as frequentam, conforme defendemos acima.

\section{Sobre o autores}

Armando Paulo Ferreira-Loureiro é doutor em Educação. Professor da Universidade de Trás-os-Montes e Alto Douro. Director do Mestrado de Educação de Adultos e Membro da Comissão directiva do Doutoramento em Ciências da Educação e vice-presidente da Escola de Ciências Humanas e Sociais da mesma Universidade.

Margarida Vilhena-Soares é professora no Ensino Secundário.

Helena Santos-Silva é doutora em Educação pela Universidade de Trás-OsMontes e Alto Douro/Portugal. Professora Associada da mesma Universidade.

\section{Referências}

Aguiar, M. B. (2009). Mediação EFA: novos contextos, práticas e perfis na Educação e Formação de Adultos. Em Actas do // Congresso Internacional do CIDInE [Centro de Investigação, Difusão e Intervenção Educacional]: Novos contextos de formação, investigação e mediação. ISP: Gaia.

Alarcão, I. (2009). Formação e supervisão de professores. Uma nova abrangência. Sísifo, Revista de Ciências de Educação, 8 (janeiro/ abril 2009), 119-128. Disponível em: http://www.researchgate.net/ publication/28320324_Formao_e_Superviso_de_Professores_Uma_ nova_abrangncia

Alarcão, I. \& Tavares, J. (2003). Supervisão da prática pedagógica. Uma perspectiva de desenvolvimento e aprendizagem. Coimbra: Livraria Almedina.

Araújo, S. (org.), Alonso, L.; Imaginário, L.; Magalhães, J.; Barros, G.; Castro, J. M.; Osório, A.; Sequeira, F. (2002). Referencial de competências-chave de educação e formação de adultos (nível básico). Lisboa: Agência Nacional de Educação e Formação de Adultos, ANEFA. Disponível em: http://www.catalogo.anqep.gov.pt/boDocumentos/ getDocumentos/144

Bardin, L. (1977). Análise de conteúdo. Luis Antero Reto e Augusto Pinheiro (trads.). Lisboa: Edições 70. Lisboa: Edições 70.

Bogdan, R. \& Biklen, S. (1994). Investigação qualitativa em educação. Porto: Porto Editora. 
Canário, R. (1999). Educação de adultos: um campo e uma problemática. Lisboa: Educa.

Comissão das Comunidades Europeias (2000). Memorando sobre aprendizagens ao longo da vida. Bruxelas: Serviço das Publicações Officiais das Comunidades Europeias. Disponível em: http:// dne.cnedu.pt/dmdocuments/Memorando\%20 sobre\%20Aprendizagem\%20Longo\%20da\%20 Vida\%20pt.pdf

Comissão Europeia (1995). Livro Branco sobre a educação e a formação. Ensinar e aprender. Rumo à sociedade cognitiva. Bruxelas: Serviço das Publicações Officiais das Comunidades Europeias. Disponível em: https://www.forma-te.com/mediateca/ finish/114-forma-te/27637-livro-branco-sobre-a -educacao-e-a-formacao

Dubar, C. \& Gadéa, C. (2001). Sociologia da formação pós-escolar. Em Philippe Carré \& Pierre Caspar (dirs.). Tratado das ciências e das técnicas da formação, 143-160. Lisboa: Instituto Piaget.

Finger, M. (2008). A educação de adultos e o futuro da sociedade. Em Rui Canário \& Belmiro Cabrito (orgs.). Educação e formação de adultos. Mutações e convergências, 15-30. Lisboa: Educa.

Flecha, R. (1997). Compartiendo palabras: el aprendizaje de las personas adultas a través del diálogo. Barcelona: Paidós.

Freire, P. (1975). A pedagogia do oprimido. Porto: Afrontamento.

Gento-Palacios, S. (2004). Supervisión educativa. Madrid: Sanz y Torres.

Glickman, C. D. (1985). Supervision of Instruction. A Developmental Approach. Boston: Allyn and Bacon.

Gomes, M. do C. (coord.) (2006). Referencial de competências-chave para a educação e formação de adultos - nível secundário: guia de operacionalização. Lisboa: Direcção Geral de Formação Vocacional. Disponível em: http://www.catalogo. anqep.gov.pt/boDocumentos/getDocumentos/146

Gomes, M. do C. \& Rodrigues, S. (2007). Cursos de educação e formação de adultos - nível secundário. Orientações para a acção. Lisboa: Agência Nacional para a Qualificação, I.P. Disponível em: http://www.anqep.gov.pt/aaaDefault.aspx?f= $1 \&$ back $=1 \&$ codigoms $=0 \&$ codigono $=6302 \mathrm{AA}$ AAAAAAAAAAAAAAAA\&back =1\&chave = cursos $\% 20$ efa\&tema $=$ all \&advance $=4$

International Commission on the Development of Education (1972). Learning to Be. The World of Education Today and Tomorrow. Paris: United Nations Organization for Education, Science and Culture, UNESCO. Disponível em: http://www. unesco.org/education/pdf/15_60.pdf
Knox, A. B. (1993). Strengthening Adult and Continuing Education: A Global Perspective on Synergistic Leadership. San Francisco: Jossey-Bass.

Loureiro, A. (2008). As organizações não-governamentais de desenvolvimento local e sua prática educativa de adultos: uma análise no norte de Portugal. Revista Brasileira de Educação, 13 (38), 221-238. Disponível em: http://www.redalyc. org/articulo.oa? id $=27503803$

Loureiro, A. (2010). Um centro de educação e formação de adultos que aprende. Educação em Revista, 26 (2), 43-64. Disponível em: http://www. scielo.br/pdf/edur/v26n2/a03v26n2.pdf

Merriam, S. B. (1988). Case Study Research in Education: A Qualitative Approach. San Francisco, California: Jossey-Bass

Morgado, C. \& Oliveira, I. (2009). Mediação em contexto escolar: transformar o conflito em oportunidade. Exedra, 1, 43-56. Disponível em: http:// www.exedrajournal.com/docs/01/43-56.pdf

Neves, I. (2007). A formação prática e a supervisão da formação. Revista Saber (e) Educar, 12, 7995. Disponívele em: http://repositorio.esepf.pt/ bitstream/10000/17/2/SeE12A_Formacaolvone Neves.pdf

Nóvoa, A. (2007). O regresso dos professores. Disponível em: http://escoladosargacal.files.wordpress. com/2009/05/regressodosprofessoresantonio novoa.pdf

Oliveira, L. (2009). A figura do mediador no campo da formação de adultos. Disponível em: http://www. educacion.udc.es/grupos/gipdae/documentos/ congreso/xcongreso/pdfs/t1/t1c2.pdf

Palma, F. \& Flecha, R. (1998). Educación de personas adultas. Em António Petrus (coord.). Pedagogía social, 154-177. Barcelona: Ariel.

Portugal, Decreto-Lei 115-A/98, de 4 de maio, aprova o regime de autonomia, administração e gestão dos estabelecimentos públicos da educação pré -escolar e dos ensinos básico e secundário, bem como dos respectivos agrupamentos. Diário da República, 102, 4 de maio de 1998. Disponível em: http://www.fenprof.pt/?aba $=27 \&$ cat $=76 \&$ $\mathrm{doc}=156$

Portugal, Decreto-Lei 75/2008, de 22 de abril, aprova o regime de autonomia, administração e gestão dos estabelecimentos públicos da educação pré -escolar e dos ensinos básico e secundário. Diário da República, 79, 22 de abril de 2008, 23412356. Disponível em: https://dre.pt/application/ dir/pdf1sdip/2008/04/07900/0234102356.pdf

Portugal, Ministério do Trabalho e da Solidariedade Social, Ministério da Educação, Iniciativa Novas Oportunidades, Iniciativa no âmbito do Plano 
Nacional de Emprego e do Plano Tecnológico. Disponível em: http:// www.oei.es/quipu/portugal/novas_oportunidades.pdf

Portugal, Portaria 817/2007, de 27 de julho, define o regime jurídico dos cursos de educação e formação de adultos, adiante designados por cursos EFA, de nível básico e secundário e de níveis 2 e 3 de formação profissional. Diário da República, 144, 27 de junho de 2007, 48234831. Disponível em: http://legislacao.min-edu.pt/np4/np3content/ ?newsld=1239\&fileName=portaria_817_2007.pdf

Portugal, Portaria 230/2008, de 7 de março, define o regime jurídico dos cursos de educação e formação de adultos (cursos EFA) e das formações modulares previstos no Decreto-Lei 396/2007, de 31 de dezembro, e revoga a portaria 817/2007, de 27 de julho, 1456-1470. Diário da República, 48, 7 de março de 2008. Disponível em: http://www. confagri.pt/legislaca/Portaria_230_2008.pdf

Quintana, J. (1995). Experiencias en educación de adultos. Em José Ortega-Carrillo (coord.). La educación de adultos: situación actual y perspectivas de futuro: I Congreso Internacional de Educación de Adultos, Granada (España), 1993, 191-198. Granada: Fundación Educación y Futuro.

Rodrigues, S. P. (2009). Guia de operacionalização de cursos de educação e formação de adultos. Lisboa: Agência Nacional para a Qualificação, ANQ. Disponível em: http://www.igfse.pt/upload/docs/ gabdoc/2009/Novidades/07-Jul/Guia\%20de\%200peracionaliza\% C3\%A7\%C3\%A30\%20de\%20cursos\%20EFA.pdf

Sá-Chaves, I. (1997). Percursos de formação e desenvolvimento profissional. Porto: Porto Editora.

Schön, D. A. (1983). The Reflective Practitioner: How Professionals Think in Action. New York: Basic Books.

Schön, D. A. (1987). Educating the Reflective Practitioner: Toward a New Design for Teaching and Learning in the Professions. San Francisco: Jossey Bass Publishers.

Senge, P. (2002). La quinta disciplina. Barcelona: Granica.

Sitoe, R. (2006). Aprendizagem ao longo da vida: um conceito utópico? Comportamento Organizacional e Gestão, 12 (2), 283-290. Disponível em: http://www.scielo.mec.pt/pdf/cog/v12n2/v12n2a09.pdf

Sousa, A. (2005). Investigação em educação. Lisboa: Livros Horizonte.

Vala, J. (1986). A análise de conteúdo. Em Augusto Silva \& José Madureira Pinto (orgs.). Metodologia das ciências sociais, 101-128. Porto: Edições Afrontamento.

Vieira, F. (1993). Supervisão - Uma prática reflexiva de formação de professores. Rio Tinto: Edições ASA.

Wenger, E. (2001). Comunidades de práctica. Aprendizaje, significado e identidad. Barcelona: Paidós.

Yin, R. (2005). Estudo de caso: planejamento e métodos. Porto Alegre: Bookman. 